\title{
Distribución y asentamientos de tribus bereberes (Imazighen) en el territorio emeritense en época emiral (S. VIII-X)'
}

\author{
Bruno Franco Moreno*
}

\begin{abstract}
RESUMEN
Pese a la escasa atención que esta franja del Occidente de Al-Andalus recibe en las fuentes historiográficas árabes durante el periodo emiral, algunas permiten constatar un claro predominio del elemento humano beréber sobre el árabe, como podemos apreciar en las sucesivas revueltas y enfrentamientos que durante todo el siglo IX/III estas tribus mantienen contra los emires cordobeses, el reino astur-leonés y los grupos de población muladí. Buena muestra de ello ha quedado reflejado en los topónimos de algunas poblaciones actuales de Extremadura, y en asentamientos abandonados que vienen a coincidir con los descritos en los textos de viajeros, geógrafos, historiadores y alfaquíes musulmanes.
\end{abstract}

PALABRAS CLAVE: Oeste de Al-Andalus, periodo emiral, asentamientos y tribus beréberes, Kūra de Mérida.

\section{INTRODUCCIÓN}

La presencia beréber (Amazigh) en la actual Extremadura, se remonta a los primeros momentos de la conquista y ocupación de la península Ibérica por las tropas islámicas. No obstante, poco se sabe de las características de los asentamientos norteafricanos en esta parte del Occidente peninsular, a diferencia del Šarq al-Andalus, donde sí ha despertado el interés de arqueólogos e historiadores medievalistas (BARCELÓ, 1995:8998; GUICHARD, 1969 (5) 103 y ss; BAZZANA et alii, 1998).

\begin{abstract}
In spite of the little attention given to this strip of land in the West of Al-Andalus, in the Arabic historiographic sources during the emiral period, some sources verify a clear predominance of the Berber people over the Arabs. We may appreciate this in the successive revolts and confrontations that during the whole of the IX century these tribes pursued against the emirs of Cordova, the Astur-leones kingdom and groups of the Muladi population. Convincing proof of this has been shown in the toponyms of some of the present populations in Extremadura and in abandoned settlements, which coincide with the ones described in the texts of travellers, geographers, historians and Muslim doctors (ulemas).
\end{abstract}

KEY WORDS: West of Al-Andalus, emiral period, settlements and tribes Berbers, Kora of Merida.

La valoración del papel desempeñado por el elemento humano norteafricano se ha desdeñado en exceso, tanto a nivel individual como colectivo, en la implantación y formación del estado islámico de al-Andalus, especialmente en los estudios históricos y arqueológicos desarrollados en Extremadura. Por ello se hace necesario la realización de trabajos donde se resalte esta presencia beréber; no solamente enfocados, como hasta ahora, al estudio de las rivalidades mantenidas con el estado central, sus desplazamientos continuos, su integración social,

* Consorio Ciudad Monumental de Mérida. Doctorando en el Departamento de Ha. Medieval y C.C y T.T. Historiográficas de la U.N.E.D.

I Este trabajo es un resumen de una ponencia presentada en el seminario que con el título de, Extremadura andalusí: últimos avances arqueológicos, tuvo lugar los días 8-9 de Abril del 2002 en Cáceres, organizado por la Casa de Velázquez y la Univ. de Extremadura, no llegándose a publicar las actas por motivos ajenos a mi persona. 
la geografía espacial, el papel político y militar desempeñado en este lugar de frontera, sino también a la herencia que nos han dejado como pueblo: sus métodos de cultivo en bancales, los sistemas de irrigación en terrazas y empleo de qanāt para el mismo (WATSON, 1998:225), los hábitos alimentarios y su peculiar forma de comportamiento social -la insumisión y el aislacionismo.

De ellos escribiría el gran historiador Ibn Jaldūn (TRABULSE, 1977):

"La población de estas comarcas se compone de beréberes, pueblo organizado en tribus las cuales cada una es animada por un fuerte espíritu de 'așabiyya (sentimiento de solidaridad tribal o clánica), pero sin resultado alguno, optando por repetidas insurrecciones y de apostasía; a cada momento se levantan en armas, sin dejarse contener por los rigurosos castigos que les inflingían las tropas árabes".

Su aportación total en esta franja de alAndalus fue considerablemente mayor que la presentada por los elementos árabes tanto yemeníes como qaysíes -recordemos que los yûnd sirios nunca se asentaron en este solarasí mientras no aparezcan nuevos documentos, las fuentes historiográficas árabes no dejan lugar a dudas acerca de esta abrumadora presencia de elementos norteafricanos, pues del otro lado del estrecho vinieron familias, clanes y cabilas en gran número (Al-MAQQART̄, 1984: 179).

Al comenzar este análisis se hace necesario resaltar que los datos que nos han sido trasmitidos entre los decisivos años del 71 I y 755 carecen prácticamente de valor, pues proceden en su mayor parte de época Omeya. Las atribuciones de etnia árabe o beréber en este período son escasas, las más, falseadas por autores árabes de los siglos XI y XII. Así pues, resaltar que las adscripciones tribales del período pre-omeya son casi nulas. Por tanto, la mayor parte de este estudio va a ir centrado a partir de la instauración del emirato Omeya de alAndalus.

Lo que sigue a continuación es solo una recapitulación sobre los asentamientos de tri- bus beréberes, específicamente centrado en los territorios dependientes de la M,rida musulmana, primero como capital de al-tagr al-adnà o Frontera Inferior durante gran parte del período emiral (MANZANO,1991:57), y posteriormente ya avanzado el siglo IX, como Küra (provincia) del mismo nombre, y que en líneas generales vendría a ocupar espacialmente buena parte de la actual Extremadura (VALLVÉ, 1986:316). Intentaré materializar dentro de lo posible éstos asentamientos en un mapa para hacer más práctica su fijación espacial (Fig. I). Con ello pretendo fijar el establecimiento de las confederaciones beréberes desde el primer momento de la ocupación de esta parte de la Extremadura andalusí, así como las sucesivas oleadas de norteafricanos que se introducen durante los dos primeros siglos de dominio islámico en la península; a la vez que señalar los clanes o familias más destacadas, las referencias toponímicas, la evolución histórica de estos grupos, etc.

Acerca de estos núcleos de asentamiento beréber en al-Andalus, la investigación ha avanzado considerablemente en los últimos años. Así a los trabajos a nivel general encabezados por BOSCH VILÁ (1964: 12-37; 1965: 147- 161; 1994:8396), y continuados por PIERRE GUICHARD (1969: 103-156; 1976), MOLINA LÓPEZ (1985-6: 2533), MANZANO MORENO (1990: 397-428; 1991), y HELENA DE FELIPE (1995: 185-189;1997), se añaden los de $M^{a}$. ÁNGELES PÉREZ ÁLVAREZ (1987: 101-106) y MANUEL TERRÓN ALBARRÁN (1991: 21-37) en el ámbito regional. No debemos olvidar, la celebración de Congresos y monográficos donde se tratan diversos aspectos del pueblo Amazigh ("Al-Qantara, 1990, n'. Xl"; "V semana de estudios medievales, 1994: 209-215", "Imazighen del Magreb entre Occidente y Oriente" [Introducción a los beréberes], Granada, 1994).

También hay que sumar las aportaciones de prestigiosos investigadores del otro lado del Mediterráneo como 'ABD AL-WAHID DUNNÚN TĀHĀ (1981: 35-48), y RACHID RAHA CAHMED (1994: 83-96), que han venido a subrayar la importancia del elemento norteafricano en el devenir histórico de al-Andalus, y la posterior influencia que ejercieron en sus lugares de origen a partir del siglo XI/ $\mathrm{V}$ en Almorávides, Almohades y Meriníes. 


\section{ANTECEDENTES}

Los beréberes constituyen la población característica del Norte de África, y más concretamente del Magreb. Por ello no es extraño que la ocupación de la Hispania tardoantigua fuera obra esencialmente de estos elementos norteafricanos. El primer documento historiográfico que señala este dato se encuentra en la Crónica Mozárabe de 754 (LÓPEZ PEREIRA, 1980: 68), donde se nos habla de los "Mauri" utilizando este nombre para citar unos episodios que las crónicas musulmanas posteriores reservaban para los beréberes (GONZALBES, E., 1994: 19ss). Estas descripciones coinciden con los "mauri" de los autores grecolatinos para narrar las invasiones que tuvieron lugar en regiones de la Bética a mediados del siglo II d.C. Son por tanto sucesos que se vienen repitiendo entre ambas poblaciones de las dos orillas desde hace milenios, y que en esta ocasión van a representar a la fuerza de choque de las tropas "islámicas" que van a cruzar el estrecho hacia el 7।1/92.

El historiador de origen egipcio lbn 'Abd alHakām indica en su Futūh Ifriqiya wa-I-Andalus,(VIDAL BELTRÁN, 1966:4I) obra escrita a mediados del siglo IX, que "las tropas comandadas por el liberto Târiq b. Ziyād estaban compuestas por unos 12.000 beréberes y apenas un pequeño número de elementos árabes", eso sin contabilizar las sucesivas aportaciones que va a ir recibiendo al-Andalus en años posteriores (ALMAQQART̄, 1984: 175).

No obstante, la escasez de estos datos en las fuentes escritas árabes hace difícil, aunque no imposible, el estudio de las migraciones de estos pueblos. Así tenemos las referencias a las sublevaciones protagonizadas por elementos norteafricanos que nos han sido trasmitidas por los cronistas al servicio del poder Omeya y en los siglos posteriores, los topónimos referentes a tribus y clanes beréberes que han pervivido en el nombre de algunos núcleos urbanos extremeños y de accidentes geográficos tales como; (Maquilla-Magīla, Azuaga-Zumwāga, cerro de Mingazo, arroyo, fuente, casa de Mengacha-Miknāsa), y en definitiva, en aspectos materiales como la agricultura en terrazas, los espacios hidráulicos, los restos constructivos subterráneos y de superficie, objetos cerámicos, etc.

Todo ello nos está ofreciendo continuamente datos de la presencia social y material de estos grupos norteafricanos tan olvidados en nuestra región, tanto a nivel de los estudios historiográficos, como respecto a las prospecciones arqueológicas se refiere.

\section{ESTABLECIMIENTO DE TRIBUS BERÉBERES EN AL-ANDALUS}

Solo unas cuantas fuentes historiográficas islámicas nos ofrecen datos acerca de esta presencia beréber en el primer momento de la dominación de al-Andalus. La obra de Ibn Hazm, Ŷamharat Ansāb al-cArab (LÉVIIPROVENÇAL, 1948) ha sido de las pocas fuentes que trata este tema, aunque sea pasando de puntillas si lo comparamos con las páginas dedicadas a los linajes árabes. El otro gran autor que realiza un gran trabajo sobre estos pueblos es Ibn Jald_n en su Historia de los Beréberes (SLANE, 1968: vol. IIV), que aunque de fecha tardía (S. XIV) es imprescindible para conocer las áreas de procedencia de estas tribus. De estas dos obras principales, se extrae que los elementos beréberes que participaron durante los primeros años en la dominación de la península Ibérica pertenecían en su gran mayoría al grupo de los al-Butr -tribus norteafricanas que se resistieron a la romanización, tanto romana como bizantina, con indudables prácticas paganas- (MANZANO, 1990: 419); en contraposición al tronco de los Barānis, tribus más romanizadas y asentadas en los núcleos urbanos costeros. Ambos grupos se extenderían desde la actual Túnez hasta las costas atlánticas de Marruecos (GUICHARD, 1976: 367).

No obstante, desde el primer momento de la entrada de tropas con Țāriq, no dejaron de franquear ambas orillas del mediterráneo familias y tribus de ambos troncos, al-Butr y Barānis, asentándose a lo largo y ancho de la geografía peninsular. Según nos ha trasmitido Ibn Jaldūn, la mayoría de éstas tribus norteafricanas pertenecían al tronco étnico de los Zana- 
ta y Mașmūda, así como gran número de Madyuna, Miknāsa, Hawwāra, Nafza, y Gumara. Pierre Guichard (1976: 366) siguiendo la obra de Al-Isțajīi afirma, que la población del valle medio del río Guadiana y la zona Este del actual Portugal, estaba formada por Barānis, al-Butrry Mașmūda. Así mismo, el polígrafo cordobés Ibn Hazm en su Ŷamharat, afirma que esta población beréber estaba vinculada a las zonas de frontera, y ésta lo era en una gran extensión.

Después de un análisis de las fuentes se puede conjeturar, que durante los tres primeros años de presencia musulmana en al-Andalus, las tropas comandadas por Mūsà y Ṭāriq a su vuelta del Noroeste peninsular en su más que probable paso por la ruta de la plata (al balat Hūmayd), y antes de abandonar el país, se asentaron gran cantidad de grupos beréberes en los valles medios del Tajo, Guadiana y valle del Alagón, con excepción hecha de Mérida, que quedaría como núcleo de mayoría árabe "baladî" (LEVÍ-PROVENÇAL, 1982: 5I).

Con ello se estaban siguiendo las prácticas cotidianas de asentamiento de sus lugares de origen, esto es, en los valles de los ríos y mesetas. Es importante incidir en este aspecto en relación a lo que hasta ahora se había venido insistiendo, desde que Reinhart Dozy opinara que el establecimiento de las tribus beréberes en alAndalus se debió al reparto que los árabes hicieron después de la conquista, apropiándose de las mejores tierras (DUNNUN TĀHĀ, A; 1981: 35-48, Pag. ára). Esta opinión ha sido mantenida hasta bien entrado el siglo XX por algunos de los más sobresalientes arabistas e historiadores europeos (LEVÍ-PROVENÇAL; 1982: 28,52).

Esta teoría difícilmente se sostiene hoy día, si tenemos en cuenta que el número total de elementos árabes en la península nunca sobrepasó los 40-50.000 hombres a lo largo de todo el período andalusí (CHALMETA, 1994), si lo comparamos con las continuas oleadas de población norteafricana que cruzaban el estrecho de Gibraltar, durante las primeras décadas de la conquista de al-Andalus (TÉRES, 1957: 55 y ss). Esta se puede cifrar en varios centenares de miles, aun contando con la sangría que repre- sentaría la derrota del movimiento beréber del 740-742 y las hambrunas de los años 752/6, que afectó a grandes zonas de Yillīịiya (Galicia-Norte de Portugal-Asturias-Cantabria), Astorga, Coria, Mérida y Talavera (AJBĀR MAŶMÜ'A; 1984:62).

Tampoco debemos olvidar los grupos de Nafza y Magila que vinieron con el instaurador de la dinastía Omeya de al-Andalus, 'Abd alRaḥmān I al-Dājil, el cual encontraría un gran apoyo a su causa entre las tribus y clanes norteafricanos -su madre, no lo olvidemos, era una beréber (Siby) de la tribu Nafza- (AJBĀR; 1984:57. BOSCH VILÁ; | 965:| 47-|6I). Ya en el siglo IX, tropas beréberes entrarían a formar parte de los contingentes militares Omeyas bajo el gobierno del emir 'Abd Allāh; y desde el reinado de al-Hakam II en la segunda mitad del siglo $X$, el grueso de las tropas califales serían de procedencia norteafricana (IBN IDĀRĪ, Bayān II, 4I).

\section{ASENTAMIENTOS Y TRIBUS BERÉ- BERES MÁS REPRESENTATIVOS REPARTIDOS POR EL TERRITORIO EMERITENSE (S. VIII-X)}

Una vez realizada esta pequeña introducción pasaremos a examinar el espacio geográfico que ocupaban las tribus beréberes en el territorio dependiente de la Mārida emiral (fig. I), el cual permanece prácticamente invariable durante todo el período Omeya. No obstante, hay que recordar que casi nada sabemos del dominio que los musulmanes ejercieron sobre el conjunto de las tierras sometidas a la jurisdicción administrativa de Mérida, primero como cabeza visible de la Marca Inferior y, posteriormente como kūra de su nombre. Este control casi inexistente al principio, debió de configurarse a lo largo del emirato de la mano de los elementos muladíes y beréberes, no siempre fieles a las directrices de Córdoba, asentándose provechosamente en las fértiles vegas del Guadiana, el valle del Alagón, y el valle medio del Tajo, así como en las inmediaciones de las principales vías de comunicación.

Aparte de establecerse en los enclaves más significativos repartidos por el territorio, como 
indican las fuentes cuando hacen alusión a los levantamientos contra el poder central, estas tribus se dispersarían por pequeñas alquerías (qarya), constituidas por un reducido número de viviendas y dependencias -normalmente de una deficiente calidad constructiva- en las que habitaban familias vinculadas por lazos tribales, de tipo clánico, dedicados al pastoreo de los alrededores y al cultivo de regadío, sin olvidarnos de las incursiones contra otras tribus, para conseguir ganado, esclavos y mujeres. Pero sobre todo debemos destacar la importancia que representa en la economía de estos grupos, la agricultura y las nuevas practicas de cultivo; ya que la historiografía más tradicional hace remontar estos sistemas de riego al período romano, sin que tengamos en cuenta el gran impulso y desarrollo que les confirieron estos pueblos del norte de África a los métodos de regadío subterráneos y de cultivo en terrazas (GLICK, 1970). Aunque se conocen obras de irrigación en la lejana antigüedad, muchos de ellos habían sufrido un deterioro muy notable durante los siglos V-VIII, como puso de manifiesto el propio Mūsà lbn Nușāyr, al afirmar que no existía ningún canal en uso en todo el país en el momento de la conquista de Hispania (GLICK, 1997: 40).

Estos asentamientos estarían distribuidos por distritos, normalmente en alto, dependientes de la jurisdicción de Mérida, algunos con topónimos de tribus beréberes, que normalmente se mantenían aparte de la población indígena. Hoy día no sabemos distinguir los asentamientos con presencia indígena de la beréber, aunque una de las claves para analizar los asentamientos y posterior desarrollo de estos grupos norteafricanos en esta parte del territorio emeritense, debería ir en la dirección de la creación de grupos de trabajo que dedicaran una especial atención a los sistemas de irrigación por los métodos anteriormente descritos -por oposición a los de secano-, lo que nos indicaría una particular forma de la ordenación del territorio, como ha expuesto en repetidas ocasiones MIQUEL BARCELÓ (1986).

Ello demostraría una clara diferenciación con respecto a los espacios agrarios anteriores (etapa romana y visigoda), y una similitud con parale- los sitos en el Norte de África. Esto nos sería de gran ayuda a la hora de definir sus lugares de asentamiento y la ordenación del territorio con referencia a otros grupos indígenas: mozárabes y muladíes, así como una muestra del gran estado de autonomía del que gozarían estas tribus en relación al poder central.

Unos años antes de hacer su aparición cAbd al-Raḥmān I al-Dājil en al-Andalus, se desarrollaron unos acontecimientos en Mérida, bajo el gobernador Tacalaba b. Salama (742-743//24$125 \mathrm{H}$.), en los que se hace evidente que estas tribus beréberes no habían alcanzado aun el estadio de vida sedentaria en el territorio dependiente de Mérida, produciéndose un gran movimiento migratorio en el que participaban hombres, mujeres y niños. Estas prácticas conllevaría que fuesen posteriormente derrotados y puestos en cautiverio en las inmediaciones de Mérida por las tropas árabes lideradas por los walies o gobernadores de al-Andalus (AJBĀR MAŶYMU'A; $1984: 53$ trad.).

Será posteriormente con la instauración del emirato Omeya, cuando cambien las pautas de nomadismo de las tribus beréberes asentadas en al-Andalus, ello sin contar con las continuas aportaciones de nuevas tribus en los siglos venideros. Todo esto, unido a su forma de trasmisión tradicional -estrictamente oral-, ofrece algunas dificultades a la hora de constatar relatos o sucesos acaecidos a la mayoría de estos pueblos que hayan podido ser reflejados en las fuentes historiográficas árabes, viéndose relegados por tanto en la memoria histórica al olvido, como ha manifestado en numerosas ocasiones PEDRO CHALMETA (1996: I I2).

De las referencias que la toponimia nos ha dejado para vislumbrar posibles asentamientos norteafricanos en el territorio que depende administrativamente de Mérida - dejando a un lado la poca confianza que esta puede proporcionarnos en algunos casos-, sobresalen los nombres de algunas tribus: Nafza, Hawwāra, Miknāsa, Zuwwāga, Zanata y Magīla, que ostentan denominaciones tribales beréberes, estando pendientes de un estudio en profundidad por parte de los filólogos, que nos pueda ofrecer una más amplia información al respecto. 
A toda la amplia zona que se encuentra a noreste de Mérida, las fuentes historiográficas árabes la denominan Nafza, lo que se corresponde con la tribu del igual nombre. Esta designa una gran región comprendida entre los cursos medios del Tajo y del Guadiana. En el Muqtabis II (IBN HAYYĀN, 1959: 349), durante la sublevación de Ibn "al-Qitt", se cita a un visir beréber durante el Califato de Al-Hakām II presente en aquellos acontecimientos, donde se afirma que el asentamiento de Nafza se encontraba ubicado junto al Guadiana, de donde fueron enviados cartas y emisarios a Mérida, Badajoz y Toledo.

Así mismo, en el Muqtabis $\vee$ (HAYYĀN, 1981.ed. y tr.157) durante el califato de 'Abd alRaḥmān III, se citan los territorios próximos a Mérida que pasaron a poder de la autoridad Omeya. Este texto describe el hīșn de Um$\hat{Y} \hat{a}^{c} f a r$, donde se dice que era la capital de los Nafza en aquella zona. Este asentamiento fue identificado por Félix Hernández Jiménez con Mojáfar, situado muy cerca de Villanueva de la Serena, entre los ríos Guadiana y Zújar (HERNÁNDEZ, 1960: 335).

No obstante, esto no invalida que existieran más núcleos con esta denominación, así también aparecen en la zona de Coria tras la revuelta de los años 786-787. Según el historiador magrebí del siglo XIII clbn cldārī, en su obra Bayān, las tropas de 'Abd al-Raḥmān I alDäjil encontraron fuerte resistencia entre los beréberes Nafza de la región centro-oeste ( ${ }^{c} \mid D \bar{A} R \bar{T}$; 1999: 84), siendo posteriormente sometidos después de causarles un gran número de bajas.

El geógrafo al-Iștajīi menciona que la región al norte del Duero había estado poblada por beréberes Miknasíes y Nafzíes, ambos del tronco de los Butr, con anterioridad a la sublevación beréber del 740 y a las hambrunas del período 752-756. Estos hechos les obligarían a asentarse al NO. de al-Andalus, al norte del Guadiana, en las plazas de Mérida, Talavera, Coria, toda la región portuguesa del Alentejo, y por otros lugares de la actual Extremadura donde eran muy superiores en número a los árabes.
Pertenecientes a la tribu de los Miknāsa eran los Banū I-Afțas o Banū Maslama, cuyos antepasados se habían establecido en la kūra de Fahș al-Ballüt (Valle de las bellotas), y que posteriormente en el siglo $\mathrm{Xl}$, serían señores de Badajoz, Santarem y todo el țagr al-Yawfi o Marca Inferior. Acerca de la ubicación de la Miknāsa extremeña se ha escrito mucho, pero sigue sin ser rescatada del olvido. Los Miknāsa que se establecieron en esta parte del Oeste peninsular, lo hicieron entre Talavera y Cáceres, y hacia el Valle de los Pedroches "Fahṣ al-Ballūțt" (DUNNŪN TĀHĀ, 1981: 40). El geógrafo AL-IȘTTARĩ (1927: 44) la ubica a cuatro días de Córdoba; GUICHARD indica que es el nombre de una de las tribus más importantes establecidas en esta parte de al-Andalus (1976: 366 ss). FÉLIX HERNÁNDEZ la sitúa en el valle medio del Guadiana cercana al actual pueblo de Acedera (1960: 348ss), por su parte TERRÓN ALBARRÁN (1991: 31 ss), se inclina por enclavarla en el Peñón de Cogolludo, muy cerca de donde la situaba Félix Hernández Jiménez.

El geógrafo al-Idrīsī (MIZAL, 1989: 192) en su Uns al-Muhāy wa-Rawd al-Fural, la sitúa a una etapa de Cáceres, a dos de Majadat al-Balāt y a cinco de Córdoba, por tanto, entre los límites actuales de Cáceres, Trujillo, Mérida y Villanueva de la Serena. Siguiendo esta misma fuente (PÉREZ ÁLVAREZ 1992: 304 ss), en una reciente publicación, fija la medina de Miknāsa al-Asnām en la actual Zalamea de la Serena, a sudeste de donde es situada por la mayoría de los trabajos expuestos hasta la fecha. De lo que no hay duda una vez examinados las diferentes itinerarios propuestos, y las jornadas que son descritas entre otros por alIștajrī, al-Idrīī e Ibn Hawqal, es que la madīna que así es denominada Miknāsa al-Asnām, se encontraría a Noreste de Mérida, entre el Tajo y el Guadiana; aunque seguramente daba nombre a un extenso territorio situado entre ambas corrientes fluviales.

De la obra anteriormente citada de al-Idrisī, "los caminos de al-Andalus" (MIZAL, 1989: 86), en el itinerario que parte de Córdoba a Miknāsa, el autor refiere una serie de núcleos habitados, con sus correspondientes distancias entre ellos, a cuya mayoría podríamos situar 
en el mapa. Así se partía de Córdoba a Obejo (Ubāl) equidistantes 24 millas, después a Pedroche (Bitrawŝs ) una etapa, de aquí a Santa Eufemia (Šant Qüniyya) I 8 millas, de ésta población se partía a Šant Q.R.Q. ? doce millas, de aquí a Capilla (Kabbāl) doce millas, para pasar a continuación a B.t.r.l.š (Arlitos o Garlitos) en ARJONA CASTRO (200 I: 167 ss) ocho millas, que se corresponde perfectamente con la distancia de 10 kilómetros que hay entre ambas localidades. Después prosigue camino hacia Qunayțarat Balà (Puentecillo de Balì o Balà), doce millas, muy cerca de Navalvillar de Pela y su entorno jurisdiccional, donde Félix Hernández situaba Miknāsa, en la Sierra de Pela en la margen derecha del río Guadiana. De este último enclave se parte hacia Tâlüt?, doce millas, y de aquí a Miknāsa 18 millas; esto podría ayudarnos a situarla, si trazamos una línea recta en la dirección noroeste que mantiene el itinerario propuesto por el autor, relativamente cerca del Puerto de las Herrerías, donde aparecen varios topónimos del tipo (Fuente de Mengacha, Arroyo de Mengacha, Cortijo de Mengacha, Casas de Mengacha), que recuerdan al nombre de esta tribu beréber y su probable lugar de asentamiento (Mapa Cartográfico el Ejército, serie L, hojas 12-29; | |-30).

Aunque como se dijo con anterioridad, ocuparía una amplia franja territorial que abarcaría seguramente gran parte de los actuales términos municipales de Alcuéscar, Arroyomolinos, Valdemorales y Almoharín. No obstante, no debemos olvidar las imprecisiones que existen en las distancias entre poblaciones, que la mayoría de autores árabes refieren en sus obras, ya que eran tomadas éstas de terceras personas y muy rara vez eran verificadas personalmente, dando con ello lugar a frecuentes errores de cálculo.

De todo ello se deduce la necesidad de llevar a cabo las pertinentes prospecciones arqueológicas sobre dicho asentamiento beréber, en el que se puedan datar restos materiales islámicos de este período (S.VIII-X), con lo que podríamos avanzar notablemente en el emplazamiento de tan misteriosa madina (FRANCO Y SILVA, 2001:(59-172).
La tribu Hawwāra es otro de los grandes grupos norteafricanos que penetraron en la península Ibérica junto con Taārik en el 7/ I/92. A ella pertenecían los Banū Farfarinn, familia importante de Medellín, por tanto importante enclave Hawwarí, algunos de cuyos miembros también residían en Mérida (ŶAMHARA;50I). Respecto a su ubicación espacial dentro del territorio emeritense, esta no puede ser más confusa después de examinar los datos que nos han legado la historiografía andalusí. AlIștajrī la sitúa entre Miknāsa y Nafza, a cuatro días de la primera y a diez de la segun$\mathrm{da}$, distancias que sin duda se deben a un error del copista, sobre todo si tenemos en cuenta una noticia que nos ha trasmitido lbn Hayyān 1981: 159) en su muqtabis $V$, donde cAbd al-Rahman III an-Nasir, nombró para la ciudad de Mérida en el 928/316 H. un 'āmil, bajo cuyo gobierno decidió poner a Miknāsa, Hawwāra, Nafza y Laqant, asentamientos todos ellos dependientes jurisdiccionalmente de Mérida.

Los Zuwwāga son otra de las tribus beréberes que han dado nombre a una población dependiente administrativamente de Mérida, sita en el sureste de Badajoz -la actual Azuaga, -pertenecientes al tronco de los al-Butr. Ibn Jaldūn los considera ligados por lazos familiares con los Zanāta, tribu también de los Butr que se asentó en la franja sur del territorio emeritense y en las comarcas vecinas de Firrís y Fahș al- al-Ballüt, en plena Sierra Morena. El polígrafo cordobés Ibn Hazm los sitúa también en Laqant, cerca de Fuente de Cantos y Badajoz (ŶAMHARA: 464).

En Mérida encontramos elementos de la tribu Mașmūda en el siglo IX, procedentes de Coria y Egitania (Idanha ha vella), los famosos Banū Tâŷ̀t de los cronistas, que expulsaron a miembros de la tribu Kutama establecidos en Mérida a finales del siglo IX (ŶAMHARA: 466). Ibn Tāŷit se apoderó de la ciudad después que Muhammad arrasara sus murallas en el 868 , enfrentándose posteriormente con el célebre rebelde muladí Ibn Marwān al-Ŷillīīi, según nos ha trasmitido Ibn Hayyān en el Muqtabis $V$ (1981: 99-100). 
También eran beréberes los vecinos de Qal'at al-Hanš (Alanje), de la tribu Kutama pertenecientes al tronco de los Barānis, procedentes de Saktān o Suktān, muy cerca del actual pantano de Azután (VALLVÉ, J., 1996: 275) en la actual provincia de Toledo, que a raíz de verse asaltados por las huestes cristianas se asentaron en sus alrededores. Estos serían con posterioridad cruelmente derrotados por las tropas del rey Leonés Ordoño II, en las correrías llevadas a cabo por la Frontera Inferior durante el año 915-16 (HAYYĀN, Muqtabis V; 1981: 102).

Otra tribu importante son los Magilíes pertenecientes a los al-Buttr, quienes prestaron apoyo a cAbd al-Raḥmān I al-Dājil, y de quienes no se vuelve a tener noticias hasta un siglo después, cuando un tal Karim b. llyas, al servicio de los Omeyas, ocupa un territorio conocido con el nombre de la tribu en la küra de Sidonna (Sidonia), dando también nombre a la actual Maguilla, localidad situada a pocos kilómetros de Azuaga (GUICHARD, 1976: 379ss).

Igualmente, hay presencia norteafricana perteneciente al clan de los Șadfüra, los cuales provienen del distrito de Fahș al-Ballüț. Estos también pertenecían al grupo de los al-Buttr, del que encontramos testimonio en Medellín (Madalīn), donde era su jefe Abu Zaâbal al Sadfuri el cual daba nombre a su nisba (IBN IIDĀRI, 1999: 82). Este jefe beréber se enfrentaría al poder central aliándose en la revuelta que protagonizaría Al-Hasan ben Aly (apodado el fatimí), oriundo de Mequinenza de la Idua, durante la década del 770-780/ 160.

Como hemos visto hasta ahora, muchas de estas Cabilas se asentarían por grupos, apartados del resto e intentando escapar del control Omeya, eligiendo para ello lugares altos y fácilmente defendibles. Aunque los cronistas al servicio del poder Omeya toquen tangencialmente las áreas de asentamiento o de control beréber-todo su interés radicaba en los núcleos urbanos de mayoría árabe- las obras de estos escribas, geógrafos, historiadores, alfaquíes -sobre todo en los diccionarios biográficos- (FELIPE, H. de, 1995: 185), refieren hechos donde se ven indicadas algunas de las nisbas de procedencia beréber y el lugar donde se encuentran ubicadas geográficamente. Así para el territorio dependiente jurisdiccionalmente de Mérida, las noticias -aunque no excesivasson suficientes para mostrarnos la importancia de éstos grupos humanos. En este plano podemos situar expresiones como "min al-barbar" o "min barbar Mārida" que son bastante frecuentes en los diccionarios andalusíes, y que nos están refiriendo la importancia de este poblamiento en todo el "țagr" Inferior a finales del siglo IX y comienzos del X (FELIPE, H. de, 1997: 23).

Desde el primer momento las fuentes escritas árabes hacen referencia a población beréber asentada en el entorno de la ciudad de Mérida. En el 'Ajbār se describen los levantamientos que se suceden entre el 740 y 742, así como las expediciones de 'Abd al-Rahmān al-Däjil contra las insurrecciones protagonizadas por estos grupos -la de Šaqyà al-Miknāsī, rebelión que dura cerca de diez años(768-777) - la cual se extenderá por las comarcas de Coria, Santaver, Medellín y toda la zona Norte de Mérida (AJBĀR MAŶYMÜ'A; 1984: 107).

Años más tarde, bajo el emirato de alHakam I (796-822), un miembro de los Banu Wansūs, Asbag b. 'Abd Allāh protagonizó un nuevo levantamiento que duraría siete años, al cabo de los cuales solicitó el aman y se trasladaría a Córdoba (IBN HAYYĀN, 200I: 45-48). Este ‘Abd Allāh b. Wansūs pertenecía también a la tribu Miknāsa, lo que nos da muestra de la importancia de este asentamiento en la kūra. Después de desarrollarse en Mérida un rosario de insurrecciones durante este período, al final del gobierno del emir al-Hakam I, se produce un nuevo rebrote de rebelión protagonizado por un miembro de la tribu Mașmūda, Mahmūd b. 'Abd al-Yabbār, que junto con la colaboración del muladí, Sulaymān bn. Martīn tendrán en jaque a las tropas emirales. Esta rebelión finalizará con el asedio que sufre la ciudad con 'Abd al-Raḥmān II en el 832-833 y con la muerte del masmudí Mahmüd cAbd al-Yabbār (IBN HAYYĀN, 2001:298-307), dando paso a continuación a la construcción de la alcazaba maridí, para controlar en lo posible las continuas insurrecciones que tenían lugar en la ciudad y su entorno. 
No faltarán los levantamientos en Mérida bajo los emires Muhammad y ${ }^{\mathrm{C} A b d}$ Allah hasta el final del emirato, produciéndose una curiosa alternancia entre beréberes y muladíes contra Córdoba: "todo al-Andalus menos Córdoba se alzó contra 'Abd Allāh: Ibn 'Awsayâ en Lisboa, Oporto y su territorio, los beréberes de Mérida,.." (DIKR BILĀD AL-ANDALUS, 1983, T. II:I64). Como asevera Helena de Felipe "Ilama la atención que Mérida sea el único enclave del que no se menciona un líder reconocido, sino que se cita de un forma imprecisa a los beréberes de Mérida" (1997:3 I4). En definitiva, esto nos estaría dando muestras de la variedad y dispersión de las tribus asentadas en su alfoz en el último tercio del siglo IX e inicios del siguiente.

Respecto a la zona de Medellín, también se hace referencia a la presencia de miembros de la tribu Hawwāra, los Banu Farfarin (Ŷamharat, 1948: 499), así como de los Mașmūda, a los que cita Ibn Hazm (PROVENÇAL, 1948:500) cuando 'Abd al-Raḥmān I al-Dājil hizo prisionero a su jefe Abu Mazkana.

Trujillo, la Turŷilla andalusí, fue también refugio de beréberes provenientes del abortado levantamiento acaecido en la kūra de Tâkurunnâ durante los años 794-796/178. Probablemente pertenecían a las tribus Nafza y Miknāsa (FELIPE, H, de, 1997: 346), manteniéndose en sus alrededores durante siglos, como indican las noticias referentes a las continuas razzias que organizaban en el país de los cristianos.

Como muestra de lo expuesto anteriormente, sirva esta breve anotación acerca de los asentamientos beréberes más representativos dependientes de la jurisdicción de la Mārida islámica según las fuentes árabes (S. VIII-X/II-IV)

Alanje: Kutama y Mașmūda. Azuaga: Zuwwāga y Zanata. Badajoz: Zanata y Miknāsa. Coria: Mașmūda, Nafza y Miknāsa. Fuente de Cantos: Zanata. Maguilla: Magïla. Medellín: Hawwāra, Mașmūda y Sadf ra. Miknāsa: Miknāsa. Mérida: Mașmūda, Hawwāra, Kutama y Miknāsa. Umm Ŷaffar: Nafza. Trujillo: Nafza, Miknāsa?

\section{CONCLUSIONES}

De todo lo anteriormente expuesto se deduce, que en el territorio dependiente de la Mārida andalusí durante los siglos que median entre la ocupación del mismo en el 7/3/94, hasta la implantación del Califato en el 929/300, los asentamientos protagonizados por las diferentes tribus beréberes, tanto al-Butr como Barānis, se extendían por una amplia zona que comprendería las tierras más allá del Tajo y el Guadiana en su parte intermedia. Las fuentes historiográficas árabes nos ofrecen datos con los nombres de los cabecillas y jefes de estas tribus, muchos de los cuales muestran sus nisbas, mayoritariamente pertenecientes a las tribus Nafza, Miknāsa, Hawwāra y Mașmūda. Esto nos está proporcionando datos importantes acerca de la distribución y asentamientos Ilevados a cabo por estas tribus en el espacio geográfico reseñado anteriormente. De todos modos esto no invalida la presencia de otros grupos de origen norteafricano en el territorio, como los Kutāma, Madyuna, Mistāsa, Zanata, Sinhāya, Awrāba, que son citados en las crónicas con menos frecuencia, pero que sin duda aparecen en momentos de revueltas y enfrentamientos, tanto contra el poder Omeya, como contra los reinos cristianos y los grupos muladíes.

Una pequeña ojeada a las crónicas nos muestra la preponderancia numérica del elemento humano norteafricano sobre el árabe en todo el territorio dependiente de Mérida; aunque desde el punto de vista material y de desarrollo histórico lo ignoremos prácticamente todo, como el dominio real ejercido sobre esta zona y sus lugares de asentamiento, a excepción de unos cuantos enclaves. Por ello se hace necesario una mayor cooperación entre historiadores y arqueólogos medievalistas, para llevar a cabo un mayor número de prospecciones arqueológicas que nos ayuden a situar y estudiar los escasos restos materiales de la presencia beréber en Extremadura, tanto en los núcleos urbanos como en los rurales, sin olvidar la arqueología de campo, que tan excelentes resultados está ofreciendo en el Levante peninsular. 
De lo que no hay duda, es que sin la aportación de estos pobladores del Norte de África, la empresa andalusí no se hubiera llevado a cabo, o en todo caso hubiese finalizado muchos siglos antes. No olvidemos que fueron pieza clave en el dominio de la Hispania visigoda, en el afianzamiento de las estructuras administrativas orientales durante el emirato y el califato, así como en el surgimiento del reino taifa de Badajoz en el siglo XI/N. Esto en el terreno político, pero en el material no debemos olvidar sus aportaciones en el campo de la agricultura, con la introducción de técnicas de regadío y de captación de aguas en qan,t y acequias, y los cultivos denominados "en bancales" y terrazas, que han llegado hasta nuestros días. No debemos olvidar tampoco la implantación y posterior desarrollo de nuevas especies vegetales (berenjena, alcachofa, dátiles, etc.); y de animales, especialmente ovicápridos (cabra y oveja merina).

\section{BIBLIOGRAFÍA}

AJBĀR MAŶYMÜcA, (1984): Lafuente y Alcántara, Int.y trd. Colecc. Obras arábigas, $H^{a}$ y $G^{a}$, Reed. Madrid.

ARJONA CASTRO, A., (200I): "Identificación de dos topónimos importantes en el poblamiento árabe de alAndalus, provincia de Badajoz: B.t.r.l.š (Arlitos o Garlitos) y Balà (Navalvillar de Pela)", Actas del XXVI Congreso de la Asociación española de cronistas oficiales, Badajoz, 17 19 de Noviembre 2000, pgs:167y ss.

BARCELÓ, M., (1986): “La qüestió de 'l ’hidraulisme andalusí", en Barceló, M, et alii, Les aigües cercades (els qanats de l'illa de Mallorca). Pags 9-36 P. Mallorca.

- (|99|): "Assentaments berbers i arabs a las regions del nord-est d'al-Andalus: el cas de l'Alt Penedés (Barcelona)", La Marche supèriore d'al-Andalus et l'occident chretien, Casa de Velásquez-Univ. Zaragoza, Madrid, pags:8998.

BAZZANA, A.,CRESSIER, P.,GUICHARD, P., (1988): Les chateaux ruraux d'al-andalus. Histoire et archéologie des husūn de sud-est du lEspagne, Madrid.

BOSCH VILÁ, J., (1964): "El elemento humano norteafricano en la historia de la España musulmana". Cuadernos de la Biblioteca Española de Tetuán, 2,pags: 17-37.

- (1965): "Establecimientos de grupos humanos norteafricanos en la Península Ibérica", en Atti del primer Congreso Internazionale di Studi Norte-Africani, Cagliari, pags: |47-|6|.
- (1994): "los beréberes en al-Andalus" en Imazighen del Magreb entre Occidente y Oriente (Introducción a los Beréberes). Edic.Rachid Raha Ahmed, Granada, pags: 83-96.

CHALMETA, P.,(1994): Invasión e Islamización, Madrid.

- (1996): "Asentamientos Beréberes", Batalius, el Reino Taifa de Badajoz, Madrid, pags; I05-II3.

CRÓNICA MOZÁRABE DE 754., (1980): edic. J. López Pereira, Zaragoza.

DIKR BILĀD AL-ANDALUS (Una descripción anónima de al-Andalus, 1983) Edic, Trad, Int. Notas e índices Luis Molina, Madrid, CSIC, T. I-II.

FELIPE, H. DE. (1995): "Beréberes en diccionarios biográficos norteafricanos y andalusíes" Actas del XVI Congreso de la U.E.A.I. Salamanca, pags: 185-189.

- (1997): Identidad y Onomástica de los Beréberes de alAndalus, Madrid.

FRANCO, B. Y SILVA, A.,(200I): "Nueva propuesta de ubicación del emplazamiento beréber de Miknāsa en el țagr al-Adnà o frontera Inferior de al-Andalus", en Mérida, Ciudad y Patrimonio, Revista de Arqueología, Arte y Urbanismo, n 5, Mérida, pp: I59- 172.

GLICK, T. F.,(1970): Irrigation and society in Medieval Valencia, Cambridge. Massachussets.

- (1997): Cristianos y musulmanes en la España Medieval, Madrid.

GOZALBES, E., (1994): "Los orígenes del pueblo beréber" en Imazighen del Magreb entre Oriente y Occidente. (Int. a los beréberes). Edic. Rachid R. Ahmed, Granada, 19-40.

GUICHARD, P., (1969): "Le peuplement de la región de Valencia aux deux premiérs siecles de la domination musulmane". Mélanges de la Casa de Velásquez, 5, pags: 103-156.

- (1976): Al-Andalus. Estructura antropológica de una sociedad islámica en Occidente, Barcelona.

HERNÁNDEZ JIMÉNEZ, F., (1960): "La kūra de Mérida en el siglo X" en Al-Andalus, XXV, pags: 313-37l.

IBN cABD AL-HAKAM,. ( 1966): Futūh Ifriquiya-wa-I-Andalus., edic. Vidal Beltrán, Zaragoza.

IBN HAYYĀN, (Muqtabis, 1950-1960): Kitab al-Muqtabis, góbierno del emir 'Abd Allah, edic. M. Antuña, 1937, trd. Guráieb en C.H.E. XIV-XXXI,.

- (Muqtabis V, 198I): texto árabe edit. Por P. Chalmeta y otros, I.H.A.C. Madrid, 1979.Trad. castellana, Crónica del califa 'Abderrahman III al-Nasir entre los años 91 2-942, por $M^{a}$. J. Viguera y Federico Corriente, Zaragoza.

- (Al-Muqtabis II-I, 200I): Crónica de los emires alhakam I y 'Abderrahman II entre los años 796 y 847, trd. Notas e índ. Mamūd cAli Makki y Federico Corriente, I.E.I.O.P. Zaragoza. 
IBN HAWQAL, (197|): Liber imaginis terrae, B.G.A. Bull 1967. trd. Romany Suay, M. J., La Configuración del mundo, Valencia.

IBN HAZM (1948. (ára)): ŶAMHARA ansab al-carab, edic. LevìProvençal, El Cairo.

IBN વIDĀRĪ al-Marrakusi (1999): al-bayan al-mugrib tīajbar mulūk al-Andalus wa-I-Magreb, II-III, edic Huici Miranda, Tetuán, 1953-4. Historia de al-Andalus, trad., y est-Htcocrítico, de Francisco Fernández González. Edit. Aljaima, Malaga.

IBN JALDÜN (1969): Histoire des Berbères et des dynasties Musulmanes de l'Afrique septentrional, trad. De Slane, edic. Paul Casanova, T. I-II, Paris.

- (1977): Introducción a la Historia Universal, al-Muqaddimah; estudio preliminar, revisión y apéndices de Elías Trabulse, México.

Al-IDRĪST̄, (1989): Los caminos de al-Andalus en el siglo XII, según "Uns al-Muhây wa-rawd al-Furaŷ" (Solaz de Corazones y prados de contemplación), Est. Edic. trad. y anotaciones por Jassim Abid Mizal, Madrid.

AL-ISTTAJRT̄, ( 1927): Kitāb al-masālik wa-I-mamālik, Ed. J. M. de Goeje. Biblioteca Geographorum Arabicorum, (T. I), Leyden.

AI-MAQQARĪ (Ajbār Maŷmūca-1984): trad. pasaje relativo a los primeros tiempos de la España musulmana, en el Vol I. de la obras arábigas de la R.A.H., pp:175ss.

JIMÉNEZ GADEA, J., (1994): "Asentamientos beréberes en al-Andalus", $\vee$ Semana de estudios Medievales, Logroño, pags: 209-215.

LEVİ-PROVENÇAL, E., (1982): España musulmana, vols. IV y $\vee$ de la $H^{\text {a }}$. de España dirigida por R. Menéndez Pidal, Madrid, 5a. Edición.
MANZANO MORENO, E., (1990): "Beréberes de alAndalus: Los factores de una evolución histórica", al-Qantara, Xl, pags:397-428.

- (|99|): La frontera de al-Andalus en época de los Omeyas, Madrid.

MOLINA, E., (1985-6): "De nuevo sobre los beréberes. Reflexiones en torno a un proyecto de Atlas de $\mathrm{H}^{\mathrm{a}}$. del Islam". Estudios de H'. y Arq. Medievales, 5-6, pp.25-33.

PÉREZ ÁLVAREZ, M․ A., (1987): "La población norteafricana en Extremadura en los primeros siglos de la Invasión" en "Actas Congreso Int."El estrecho de Gibraltar", Ceuta, pags: 101-106.

- (1992): Fuentes Árabes de Extremadura, Cáceres, pp:280ss.

RAHA AHMED, R., (1994): "Algunos aspectos de la Arabización de los Imazighen", en Imazighen del Magreb entre Occ. y Oriente (Int. a los beréberes) Granada, pags: 97- 104.

TĀHĀ, 'A. W. DUNNŪN., (198I): "Istiqūr al-qabācil albarbariyya fi-I-Andalus" (El establecimiento de las tribus beréberes en al-Andalus), Awraq. IV, pags: 35-48.

TÉRES, E., (1957): "Linajes árabes en Al-Andalus según la Ŷamharat de Ibn Hazm", al-Andalus XXII, pags:55- I I I.

TERRÓN ALBARRÁN, M., (199|): Extremadura musulmana, Badajoz, pp:21-37.

VALLVÉ, J., (1986): La división territorial de la España musulmana, Madrid.

- (1996): "La Cora de Mérida durante el Califato", Batalius, el Reino Taifa de Badajoz, Madrid, pags:269-279.

WATSON, A.M., (1998): Innovaciones en la agricultura en los primeros tiempos del mundo islámico, Granada. 


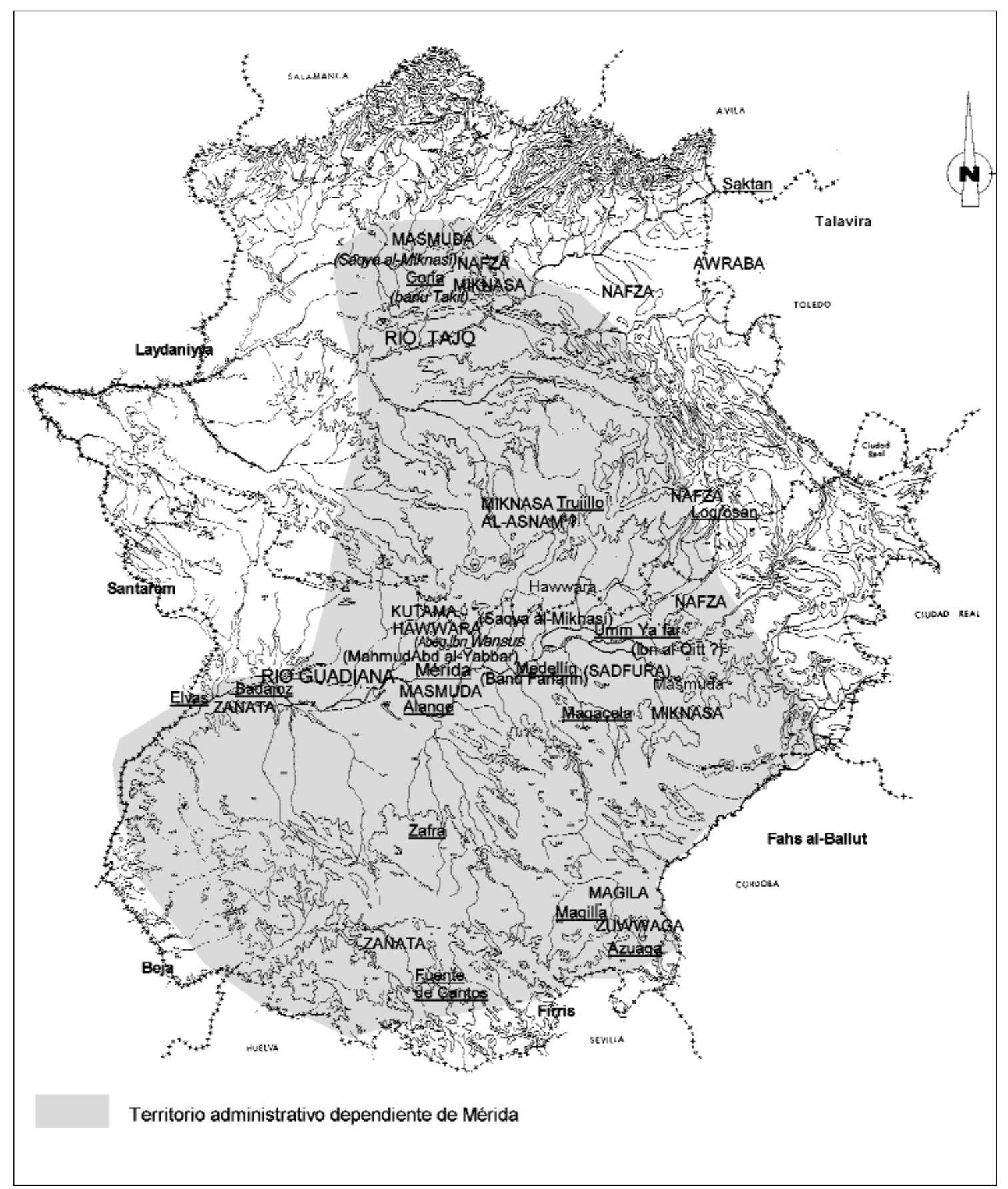

Fig. I. Asentamientos y tribus bereberes (Imazighen) durante el emirato Omeya. 